\begin{tabular}{l|l} 
REVISTA Revista Educación \\
EDUEACIÓN
\end{tabular}$\quad \begin{aligned} & \text { ISSN: 0379-7082 } \\
& \text { ISSN: 2215-2644 } \\
& \text { revedu@gmail.com } \\
& \text { Universidad de Costa Rica } \\
& \text { Costa Rica }\end{aligned}$

\title{
La organización de la Facultad de Educación en escuelas
}

\author{
Ugalde Víquez, Jesús \\ La organización de la Facultad de Educación en escuelas \\ Revista Educación, vol. 41, núm. 2, 2017 \\ Universidad de Costa Rica, Costa Rica \\ Disponible en: http://www.redalyc.org/articulo.oa?id=44051357012 \\ DOI: http://dx.doi.org/10.15517/revedu.v41i2.26240
}

Esta obra está bajo una Licencia Creative Commons Atribución-NoComercial-SinDerivar 3.0 Internacional. 


\section{La organización de la Facultad de Educación en escuelas}

\section{The organization of the Faculty of Education in Schools}

Jesús Ugalde Viquez [1]

Universidad de Costa Rica, Costa Rica

DOI: http://dx.doi.org/10.15517/revedu.v41i2.26240

jugalde@racsa.co.cr

Redalyc: http://www.redalyc.org/articulo.oa?id=44051357012

Recepción: 08 Diciembre 2016

Aprobación: 15 Abril 2017

\section{ReSUMEN:}

Este artículo presenta un análisis documental relacionado con el cambio estructural que en la década setenta del siglo XX experimentó la Facultad de Educación, al pasar de una organización interna basada en departamentos, secciones y carreras a estar integrada por cinco escuelas. Se analizan los subtemas de antecedentes y elementos del contexto educativo, causas y criterios de la nueva estructura, componentes de la estructura integrada con escuelas y aspectos de participación en el proceso de cambio hasta alcanzar la aprobación de la nueva estructura. El objetivo general y los objetivos específicos planteados orientan la búsqueda de información, respaldan el análisis de cada uno estos subtemas y facilitan la derivación de las conclusiones finales. Estas se plantean a manera de lecciones aprendidas, facilitando el conocimiento del evento histórico que se presenta, el cual se mantiene vigente aún hoy, cerca de cuarenta años después de su aprobación.

Palabras ClaVE: Educación, organización, causas, criterios, cambio.

\section{Abstract:}

This article refers to a documental analysis related with the structural change experienced by the School of Education during the seventh decade of the 20th century, when its internal structure based on departments, sections and majors was transformed into five integrated schools. The analysis is done in relation with the themes of antecedents, educational context, causes and criteria of the new structure, organizational components, and details of the participation and decision taken processes followed. The given general and specific objectives support the information search actions done and the conclusions reached are written as learned lessons, in order to facilitate the knowledge of the historical event under study, which is still valid after almost years after its approval.

KEYWORDS: Education, organization, causes, criteria, changes.

\section{INTRODUCCIÓN}

El presente artículo se refiere al desarrollo de la Facultad de Educación hasta llegar al logro de su nueva estructura organizativa conformada por la integración de cinco escuelas, realizada en los años setenta del siglo XX, tomando en cuenta, primeramente, sus antecedentes desde su incorporación a la Universidad en 1941, pasando por las acciones realizadas durante el proceso de la Reforma Universitaria de 1957 y enfatizando

\section{Notas DE AUTOR}

[1] Doctor en Educación. Profesor emérito (UCR), decano de la Facultad de Educación (1972-1979 y 1986-1989); director de la Escuela de Formación Docente (1983-1986); miembro del Consejo Superior de Educación (1972-1983); consultor de la OEA en Proyectos de Investigación Educativa y Educación de Adultos (1978-1982); consultor de la UNESCO en países de América Latina (1985-1988); asesor técnico principal, por la UNESCO, en Proyectos de Educativos, Currículum, Formación de Educadores, Educación a Distancia y Educación para el Trabajo en Guinea Ecuatorial (1990-1991), Nicaragua (1992-1999) y Guatemala (2000-2004); docente del Programa de Doctorado en Educación (UNED), San José, Costa Rica (2007-2009) y consultor de CEEC/SICA (2012-2013). Algunas publicaciones son: (a) Sistematización de enfoques de la educación en las áreas rurales de Nicaragua. Managua, 1995; (b) El constructivismo, conceptualización, desarrollo y aplicaciones. Guatemala. 2002; (c) La educación para el trabajo, una propuesta innovadora de cambio educativo y curricular en el marco de la Educación para Todos. Sistematización final. En coautoría con Juan Fernando Díaz Zuchini, Proyecto de Educación Básica para el Trabajo en Zacapa y Chiquimula, Guatemala -BEZACHI- 2004; (d) Sistematización de Proyectos Educativos a cargo de la CECC/SICA Financiados por la Cooperación Holandesa entre 1996 y 2013. En coautoría con Ana Cecilia Hernández R., Rosaura Matarrita B. e Irma Zúñiga L. CEECC/SICA, Proyecto FID-Holanda. 2010-2012. San José, Costa Rica. 2013 y (e) Sistematización de Proyectos del Área Educativa Financiados por la Cooperación Holandesa entre 1990 y 2013 en los Países Centroamericanos. CEECC/SICA, Proyecto FID-Holanda. 2010-2012. San José, Costa Rica. 2013. 
la orientación humanista de los estudios universitarios, junto con la creación de la Facultad de Ciencias y Letras, la inclusión de los Estudios Generales y la constitución de la Facultad de Educación. Se consideran también las causas de la nueva estructura, así como los criterios utilizados y el proceso de gestión seguido, desde el planteamiento de la idea, la elaboración, estudio, discusión y aprobación de la propuesta, entre otros aspectos de interés.

Los acontecimientos e ideas que se presentan se fundamentan en el conocimiento y experiencia del autor, gracias a su participación directa en el proceso de transformación, debido a su condición de Decano de la Facultad de Educación en tres períodos (1972-1975, 1976-1979 y 1986-1989), incluyendo el ejercicio del Vicedecanato en 1970/1971, la Dirección de la Escuela de Formación Docente de la misma Facultad (1983-1986) y la integración del Consejo Superior de Educación (1972-1982), en representación suplente por la Universidad de Costa Rica, durante esos mismos períodos, entre otras funciones atendidas en la Universidad de Costa Rica y en el sistema educativo nacional.

Además, en el proceso de transformación conducente a la estructura actual de la Facultad de Educación, organizada bajo la integración de cinco escuelas, se tomó en cuenta la participación y aportes académicos, intelectuales y de apoyo personal del selecto equipo de trabajo conformado por el personal docente de la Facultad, integrantes de la Asociación de Estudiantes y del personal administrativo, cada cual ejerciendo su actividad en las condiciones de trabajo heredadas de la Facultad de Educación organizada en departamentos, secciones y carreras.

Seguidamente se presentan los objetivos orientadores del desarrollo dado al tema propuesto, seguido del señalamiento de antecedentes específicos considerados pertinentes para el logro de una mejor comprensión del proceso de transformación que se analiza; se anotan las causas y criterios aplicados, se identifican los elementos filosóficos, administrativos y curriculares de la nueva estructura y, finalmente, se ofrecen las conclusiones correspondientes al desarrollo del tema propuesto.

\section{OвJetivos}

Dar a conocer el proceso de gestión académica y administrativa del proceso de transformación de la estructura organizativa de la Facultad de Educación de la Universidad de Costa Rica, hasta el logro de su integración con cinco escuelas, realizado en la década de los años setenta del siglo XX, tomando en cuenta sus antecedentes, las causas y los criterios de organización aplicados en la elaboración de la nueva estructura, junto con su análisis y detalles de su aprobación.

De manera específica se busca responder a los siguientes objetivos específicos:

- Identificar antecedentes referidos a los campos filosófico-pedagógico, administrativo y curricular del proceso que condujo a la nueva estructura de la Facultad de Educación integrada con cinco escuelas.

- Señalar las causas que justificaron en los años setenta del siglo XX el cambio de la estructura de la Facultad de Educación, pasando de una organización interna por departamentos, secciones y carreras a otra basada en la integración de cinco escuelas y un conjunto de servicios educativos de apoyo.

- Describir los elementos académicos, administrativos y curriculares que caracterizaron la propuesta de nueva estructura organizativa de la Facultad de Educación.

- Dar a conocer circunstancias del proceso de gestión, estudio y aprobación del cambio en la estructura organizativa de la Facultad de Educación, junto con aspectos de la participación y aportes del personal involucrado. 


\section{Antecedentes:}

Seguidamente se presentan algunos elementos considerados como pertinentes para ubicar históricamente y en el contexto educativo institucional, nacional e internacional, al proceso de transformación estructural de la Facultad de Educación durante los años setenta, tomando en cuenta acciones que tuvieron lugar desde el inicio de la década de los años cuarenta al incorporarse la anterior Escuela de Pedagogía a la Universidad de Costa Rica y pasando por aspectos de la Reforma Universitaria de 1957, hasta llegar al logro de su nueva estructura organizativa en cinco escuelas.

\subsection{Elementos importantes de los Decanatos de la Dra. Emma Gamboa Alvarado y María Eugenia Dengo Obregón:}

En primer lugar, María Eugenia Dengo Obregón (Dengo, 2011) señala que según Ley del 26 de agosto de 1940 e iniciando actividades académicas al principio del año 1941, se incorporó la Escuela de Pedagogía a la Universidad de Costa Rica. Esta Escuela había sido creada durante la administración de don León Cortés Castro (1936) al separar el proceso de formación de maestros de la Escuela Normal para ofrecer el Bachillerato en Humanidades, elevándose así a nivel universitario la formación de maestros y maestras, lo que representa un hito histórico importante para el país en el contexto latinoamericano; denominándose a esta como Facultad de Pedagogía, que se unió a las Facultades de Derecho, Farmacia, Agricultura y Bellas Artes en la nueva Universidad de Costa Rica. Esta Facultad universitaria contó con la dirección del Dr. Marco Tulio Salazar, su primer decano.

La misma autora citada indica que en 1947 el grupo de docentes y la representación estudiantil eligieron a la Dra. Emma Gamboa Alvarado como decana de la Facultad de Pedagogía, la que aún se localizaba en Heredia. Agrega ella que en 1948, “ante la carencia de espacio físico adecuado, se traslada a San José, no sin antes enfrentar problemas en dicha ciudad, por lo que ocupó varios lugares como la Escuela Roosevelt en San Pedro de Montes de Oca, en el viejo Museo Nacional (1950), en el edificio anterior de los Archivos Nacionales y en el viejo edificio de la Universidad de Santo Tomás de 1952 a 1956" (Dengo, 2011).

En el Congreso Universitario de 1946, la Licda. María Eugenia Dengo O. (Dengo, 2011) señala que según propuesta de los profesores Abelardo Bonilla y Enrique Macaya, se discutió la idea de impulsar los estudios humanísticos en la Universidad de Costa Rica, sustentando la propuesta en la vigencia de nuevas orientaciones que impulsaban un cambio en el modelo de sus creación el que, al pasar los años de la década cuarenta, con grandes acontecimientos nacionales y mundiales, no respondía a los nuevos conceptos organizacionales de las instituciones de educación superior. De esta manera, en un contexto de profundas discusiones, enfrentamientos y reflexiones, contando con el liderazgo y la certera dirección de la Dra. Emma Gamboa, entre los años 1953 y 1954, se llega al acuerdo de la Asamblea Universitaria del 30 de abril de 1955, según el cual se aprueba la reorganización de la Universidad de Costa Rica, creándose la Facultad de Ciencias y Letras, donde se incluyen los Estudios Generales, y la Facultad de Educación.

Los siguientes años se caracterizaron por una lucha intensa entre profesorado y dirigentes de la Universidad, particularmente de Ciencias y Letras, y en relación con la ubicación institucional y responsabilidades de la formación de docentes de segunda enseñanza. Para una parte debía ser responsabilidad de la Facultad de Ciencias y Letras y para otra de la Facultad de Educación. No fue sino hasta el 11 de noviembre de 1960 cuando la Asamblea Universitaria acordó que los estudios pedagógicos le pertenecían a la Facultad de Educación y los propiamente académicos a las respectivas instancias de la Facultad de Ciencias y Letras, entonces denominadas Departamentos (Química, Biología, Matemáticas, Física, Historia y Geografía, etc.) y los propios de Bellas Artes (Dengo, 2011). Las relaciones entre unas y otras instancias se acordó llevarlas a cabo por medio de Comisiones Coordinadoras de la Enseñanza de cada disciplina y con 
la coordinación de quien ejerciera el Decanato de la Facultad de Educación, contando con la participación de quienes estuvieran al frente de las Direcciones de cada especialidad académica. Al autor de este artículo le correspondió realizar la coordinación respectiva de este equipo de trabajo a lo largo de su gestión como Decano de la Facultad de Educación. Esta situación resultó ser conflictiva durante muchos años, hasta que en épocas recientes se llegó a proponer otras alternativas de coordinación, como la creación de Comisiones Interdisciplinarias, enmarcadas en nuevas tendencias académicas y pedagógicas.

Desde el punto de vista de la infraestructura de la Facultad de Educación, esta se ubicó en la Ciudad Universitaria, inaugurada en 1958. Contaba entonces con características adecuadas para el proceso de formación de docentes, con aulas, oficinas, espacios libres, auditorio, soda, imprenta, jardines, etc., todo ello construido con atinadas orientaciones de la Dra. Emma Gamboa. Era un edificio de amplia, cómoda y pertinente arquitectura (Dengo, 2011).

El legado de la Dra. Gamboa, compartido por sus estudiantes y colegas en la Facultad de Educación se centra, primeramente, en su enfoque pragmático e idealista de la educación, corriente que aún es posible observar en múltiples facetas del sistema educativo nacional y en procesos de formación de educadores y educadoras, todo esto producto de sus estudios enmarcados en la corriente instrumentalista del pragmatismo en la Universidad de Chicago, en la década cuarenta. En segundo lugar, sus conceptos de la educación nueva y el énfasis dado a la formación en democracia, que no solamente aplicara en la Facultad sino también en la creación y desarrollo de la Escuela Nueva Laboratorio, creada por ella en febrero de 1960. En tercer lugar, la aplicación de los conceptos de libertad y salud mental, integrados en la formación de toda persona y, particularmente, en los nuevos maestros y maestras (Ugalde, 2005).

El conjunto de valores e ideales que inspirara la Dra. Gamboa Alvarado fue compartido por distinguidos educadores, entre ellos: Mariano L. Coronado, Rafael Cortés Chacón, José Basileo Acuña Zeledón y José Guerrero, quienes junto con otros reconocidos profesionales llevaron a cabo tareas relevantes en la Facultad de Pedagogía durante esa época, a saber: Ondina Peraza, Uladislao Gámez S., María Eugenia Dengo Obregón, Elsa Orozco Carrillo, María Eugenia Polanco Ramírez, Carlos Caamaño Reyes, René van Huffel, Isacc Felipe Azofeifa y Hilda Chen Apuy. Integrantes de este selecto grupo también prestaron sus servicios durante el Decanato de la Licda. Dengo Obregón.

Es importante mencionar también la visión y participación política de la Dra. Emma Gamboa Alvarado, puesta de manifiesto en diversas ocasiones, como en su apoyo a la creación de la Asociación Nacional de Educadores (ANDE), en 1942, de la que fuera su segunda presidenta; su participación en la organización de la marcha de las mujeres de mediados de la década cuarenta, su defensa de los derechos de profesionales del sector educativo, su preocupación por la calidad de la educación nacional y su desempeño en puestos públicos en calidad de Asesora Técnica y Subsecretaria de Educación (1950).

El Departamento de Segunda Enseñanza de la Facultad de Educación en esos años ofrecía las carreras de Profesorado, compartiendo labores y estudiantes con los respectivos Departamentos de las Facultades de Ciencias y Letras y Bellas Artes, ofreció el título de Profesor de Estado inicialmente y, a partir de 1957, el de Profesor de Segunda Enseñanza con mención de la Especialidad correspondiente (Música, Biología, Matemática, Filosofía, etc.). Como carrera propia tenía en su Departamento de Educación Primaria y Preescolar las carreras de Educación Preescolar y de Educación Primaria, conducentes a los títulos de Maestro o Maestra en cada campo. Predominaba entonces el grupo de estudiantes del sexo femenino.

Además, la Facultad de Educación ofrecía una carrera en Bibliotecología, en relación con la Biblioteca Central de la Universidad y dos carreras al nivel de Licenciatura, una en Administración Educativa y otra en Orientación. La mayoría de graduados y graduadas pertenecía a los niveles de educación primaria y de segunda enseñanza, situación que varía con el tiempo de manera significativa.

De esta manera, la estructura anterior de la Facultad se componía por la Asamblea de Facultad, el Decanato, el Consejo Asesor y las Coordinaciones respectivas de los departamentos, secciones y carreras, todo lo cual se sostenía financieramente por una asignación presupuestaria anual que respondía a una planificación central 
de las actividades académicas y administrativas, responsabilidad del Decanato. Quien ejercía esta posición integraba el Consejo Universitario. Este tipo de organización interna de la Facultad se mantuvo hasta la transformación de los años setenta.

A partir de 1964 la Licda. María Eugenia Dengo Obregón, quien había iniciado su relación laboral con la Facultad de Pedagogía en 1950 en el área de Historia de la Educación, inicia labores en calidad de decana de la Facultad de Educación, gestión académica y administrativa que continúa hasta 1971. Tanto en su calidad de docente como de decana siempre destacó por sus cualidades personales y vocacionales puestas de manifiesto en el campo de la formación de profesionales de la educación, heredadas de su madre, Teresa Obregón, y de su padre, Omar Dengo, y cultivadas al compartir con distinguidos grupos educadores de su niñez y de la formación inicial y profesional, en el país y en el extranjero. Amante de la educación, compartía ideales, pensamientos, valores y actitudes, y en todo momento, muy humana en el trato con estudiantes y colegas, conservando siempre los límites del quehacer profesional.

Sus ideales, propósitos y proyectos fueron compartidos por gran cantidad de sus colegas, incluyendo al autor del presente artículo, destacan en el grupo docentes que venían ejerciendo labores desde la época de la Dra. Emma Gamboa y otra parte que ingresó durante su gestión. Se recuerda así a: Julián Zamora Dobles., Ovidio Soto Blanco., Gonzalo Soto Rodríguez. Marta Ramírez, Margarita Dobles, Edgar González Campos, Ramiro Montero Sánchez, Mario Fernández Lobo, Carlos Moya Barahona, Jorge Taylor L., María Huete de Guevara, José Joaquín Muñoz Bustos, Cecilia Cabezas Caggiano, Nora Ramírez Villalobos, Guillermo Molina Guzmán, Numa Sánchez, Efraím Rojas, Nelly Kooper, Jeffry Hutchinson Da Costa, Rodrigo Pacheco López, Ofelia Rodríguez y Mireya Hernández de Jáen, entre otros y otras.

En 1968 le correspondió a la Licda. María Eugenia Dengo Obregón enfrentar el reto que significó la creación de la Escuela Normal Superior, en Heredia, tomando como base la anterior Escuela Normal, en Heredia, para llevar a cabo la formación de profesorado para el nivel Secundario con el Título de Profesores de Estado en las distintas especialidades. Se rompía así el modelo de formación aplicado en la Universidad de Costa Rica. En ese tiempo las discusiones giraban en torno a la conveniencia o no del intercambio de docentes entre la Facultad de Educación y ese nuevo centro formador, sobre los requisitos de ingreso a las carreras y el traslado de estudiantes de un centro al otro, los modelos curriculares distintos, los niveles de calidad y hasta el ingreso a los puestos de trabajo en el Ministerio de Educación Pública por parte de quienes se graduaban de uno y otro centro formador. Todo esto demandó muchas horas de discusión, dedicación y hasta disgustos, todo lo cual se superó años después con la creación de la Universidad Nacional, la que entre otros centros formadores de educadores, estableció el Centro de Investigación y Desarrollo en Educación (CIDE).

Los elementos propios de las acciones administrativas, curriculares y presupuestario-financieras de la Facultad de Educación se mantuvieron a lo largo de la gestión de la Licda. Dengo Obregón tal y como se describiera para el período anterior, esto es, caracterizándose por una fuerte centralización de las funciones de dirección y control desde el Decanato y el Consejo Asesor, con dirección vertical desde y hacia el Consejo Universitario, del cual la decana fue una de sus integrantes.

\subsection{Elementos del contexto educativo nacional e internacional}

Seguidamente se mencionan elementos del contexto educativo del país que se consideran importantes porque influyeron en la gestión y desarrollo del proceso de transformación de la estructura de la Facultad de Educación que se analiza.

Se recuerda, en primer lugar, la propuesta del Congreso Universitario de 1946 referida al enfoque humanista de los estudios universitarios junto con las discusiones en torno a la creación de la Facultad de Ciencias y Letras, con los Estudios Generales, y la Facultad de Educación, situación que se acuerda en 1955 y se plasma, finalmente, con la Reforma Universitaria de 1957. El Artículo III de la Reorganización de la Universidad de Costa Rica por departamentos señala que "La Facultad de Pedagogía cambiará su nombre por 
el de Facultad de Educación al recibir el encargo de preparar también los Profesores de Segunda Enseñanza asumiendo todas las cátedras de carácter pedagógico" (Universidad de Costa Rica, 1954, p.1).

En el nivel nacional, según la ley No 1362, del 8 de octubre de 1951, se crea el Consejo Superior de Educación, con una organización jurídica aún vigente en la actualidad y del que la Universidad de Costa Rica tiene un representante en propiedad, usualmente el rector, y un suplente, usualmente quien ocupe el Decanato de la Facultad de Educación, puesto que ocupara el autor de este artículo durante los años setenta y temprano en los años ochenta.

El 30 de mayo de 1953 la Asamblea Legislativa promulga la Ley N.o 1581 referida al Estatuto de Servicio Civil (República de Costa Rica. Asamblea Legislativa, 1977) y el Decreto Ejecutivo de N.o 21 del 14 de diciembre de 1954 dicta su Reglamento. Luego, por Ley N.o 4565 del 27 de abril de 1970, se complementa ese marco jurídico con el Título II De la Carrera Docente, en cuyo artículo 53 se indica, entre otros fines, los siguientes:

a) Establecer la docencia como carrera profesional.

b) Exigir al servidor docente, la necesaria solvencia moral y profesional...

c) Velar porque el servidor docente labore dentro del campo específico de su formación profesional y académica.

d) Establecer las jerarquías de la carrera docente...

e) Dignificar al educador costarricense. (República de Costa Rica. Asamblea Legislativa, 1970, p.1)

En el capítulo VII de la clasificación del personal, dicha Ley ordena los distintos grupos y categorías, destacando al efecto lo indicado en los artículos 118 al 150 referidos a los niveles, áreas, grados y categorías en que agrupan los profesionales docentes (KT: Enseñanza Preescolar, P: Enseñanza Primaria, MT: Enseñanza Media, V: Enseñanza Técnica, etc. (República de Costa Rica. Asamblea Legislativa, 1970).

Ese señalamiento de grupos y categorías sirvió de base para respaldar los cambios curriculares hechos durante el proceso de transformación a cargo del autor del presente artículo en su calidad de Decano de la Facultad de Educación que nos ocupa al proponer también el cambio del Título de Profesor de Segunda Enseñanza por el de Bachiller en la Enseñanza de cada una de las especialidades (Biología, Química, Español, Inglés, Música, etc.), con el cual se podía acceder directamente al grupo MT4, situación que no se daba anteriormente y que conllevaba un mejoramiento laboral y salarial.

$\mathrm{Al}$ lado de esa transformación curricular, realizada paralelamente al proceso de cambio de la estructura organizativa de la Facultad de Educación integrándola con escuelas, se crearon también los bachilleratos universitarios en las distintas especialidades que ofrecía la Facultad de Educación (Orientación, Educación Especial, Artes Industriales, Bibliotecología, Educación Física, Administración Educativa, Educación Preescolar y Educación Primaria), lo que favorecía a quienes se graduaban por su acceso a los grupos y categorías correspondientes al acceder a niveles más altos y mejor remunerados de acuerdo con las escalas de cada nivel o especialidad educativa.

República de Costa $\mathrm{R}$

El 24 de setiembre de 1957 la Asamblea Legislativa promulga la Ley Fundamental de Educación, plenamente vigente en la actualidad, cuyo artículo 2 puntualiza los fines de la educación costarricense, abarcando enunciados amplios y de alto valor formativo, como son: "La formación de ciudadanos amantes de la patria, conscientes de sus deberes, de sus derechos y obligaciones, de sus libertades fundamentales, con profundo sentido de responsabilidad y de respeto a la igualdad humana...", "Contribuir al desenvolvimiento pleno de la personalidad humana...", "Formar ciudadanos para una democracia en que se concilien los intereses del individuo con los de la comunidad...", "Estimular el desarrollo de la solidaridad y la comprensión humanas" [y] "Conservar y ampliar la herencia cultural, impartiendo conocimientos sobre la historia del hombre, las grandes obras de la literatura y los conceptos filosóficos fundamentales” (República de Costa Rica, Asamblea Legislativa, 1957, p. 1). 
Además, el Capítulo III de esta ley se dedica al tema de la formación del personal docente y en su artículo 24 indica:

La formación de profesionales docentes deberá: “(a) Inspirarse en los principios democráticos que fundamental la vida institucional del país y en el criterio sobre la educación que establece el artículo 77 de la Constitución Política. (b) Asegurar al educador una cultura general y profesional y los conocimientos especiales necesarios para el buen servicio docente, y (c) Promover en el educador la formación de un genuino sentimiento de los valores de la nacionalidad, el aprecio de los valores universales y la comprensión de la trascendencia de su misión” (República de Costa Rica, Asamblea Legislativa, 1957, p. 5).

El artículo 77 de la Constitución Política citado indica que: "La Educación pública será organizada como un proceso integral correlacionado en sus diversos ciclos, desde la pre-escolar hasta la universitaria" (Rivera, 2005, p. 27).

En cuanto a la educación secundaria, es importante recordar que en 1963 se llevó a cabo un Congreso Pedagógico en el cual se discutieron opciones necesarias para transformar este nivel educativo, se modificaron los planes de estudio entonces vigentes y se impactó el proceso de formación de docentes de este nivel. Se buscaba entonces superar el énfasis dado a la memorización e información factual con el propósito de atender mejor el desarrollo del adolescente de manera más integral, con respeto a sí mismo y a otras personas junto con la búsqueda de mayor justicia social.

En el ámbito del ejercicio profesional de la educación en el país, se recuerda que el 28 de octubre de 1972 la Asamblea Legislativa promulgó la Ley N.o 4770, creando el Colegio Profesional de Licenciados y Profesores en Letras, Filosofía, Ciencias y Artes (COLYPRO), mediante transformación del Colegio de Licenciados en Letras y Filosofía, que había sido creado el 20 de noviembre de 1950, según Ley N.o 1231, para dar cabida a educadores y educadoras que obtuvieran los títulos de Profesor, que aún existían, y de Bachillerato Universitario, creados en los años setenta, entre otros títulos y grados en las distintas ciclos, niveles y especialidades educativas (República de Costa Rica, Asamblea Legislativa, 1972).

Entre los años 1970 y 1974, cuando era Ministro de Educación el Prof. Uladislao Gámez S., el Gobierno de la República promulgó el Decreto Ejecutivo N.o 3333-E Plan Nacional de Desarrollo Educativo (1974), enmarcado en movimientos de reforma educativa de la década setenta y como resultado de un proceso de planificación vertical, centralizado, en busca de un proceso de desarrollo progresivo para la educación, el cual se llevó a cabo y ofreció un cambio sustantivo en el sistema educativo costarricense. Este plan se orientó en tres finalidades, a saber:

a) Elevar el nivel educativo promedio de la población, particularmente en zonas hasta ahora menos favorecidas; a fin de conseguir la integración nacional, poner a todos los costarricenses en mejores condiciones de vida, y contribuir así al desarrollo socio-económico del país.

b) Modernizar el sistema educativo para que responda a las necesidades sociales y económicas del país y favorecer el proceso de desarrollo.

c) Mantener en sus límites el peso porcentual del presupuesto educativo con respecto a las finanzas nacionales, sin perjuicio del mejoramiento de la enseñanza en calidad y cantidad. (Ministerio de Educación Pública, 1973, p. 9-13)

A cada uno de estas finalidades se le señalaron los correspondientes objetivos específicos que guiaron las acciones de cambio durante el proceso de aplicación del Plan. Se establecieron entonces los distintos ciclos y niveles educativos, actualmente vigentes, que incluyen la educación preescolar, la educación general básica (con nueve años de duración y dividida en tres ciclos de tres años de duración cada uno), y el nivel de la educación diversificada, con sus divisiones en las ramas académica y técnica. Además, se impulsaron cambios en el proceso de evaluación de los aprendizajes donde la Facultad de Educación brindó apoyo por la vía de la capacitación docente.

De manera específica, en cuanto al campo de la formación de docentes, el Plan Nacional de Desarrollo Educativo (1974) señalaba "la necesidad de formar todos los tipos de personal que requiere el sistema 
educativo, y no sólo maestros y profesores. La necesidad de adecuarse, no sólo a los fines generales de toda educación, sino además concretamente a las características el sistema educativo costarricense en cuanto a su estructura, sus objetivos cualitativos, sus servicios especializados, etc. la necesidad de que todo educador sea su "especialidad", se sienta y actúe ante todo como parte de un sistema de educación integral; es decir, que sea un educador antes que un especialista. Se procurará que además de los estudios específicos del plan de formación de educadores se integre en todos los casos contenidos de ética profesional, y con nociones básicas de orientación” (Ministerio de Educación Pública, 1973, p. 52).

En este conjunto de antecedentes nacionales destaca también el desarrollo e implementación del Proyecto de Regionalización Educativa que se llevó a cabo de 1978 a 1982, cuando la Licda. María Eugenia Dengo Obregón, ministra de Educación, contó con el apoyo y participación significativa de personal de la Facultad de Educación, por medio de actividades de investigación y desarrollo curricular inspiradas en la apertura de mayores espacios para la participación comunitaria en el proceso educativo, de manera que cada sujeto de la educación (estudiantes, docentes, padres y madres de familia, comunidades) actuaron como parte activa en la gestión educativa y del desarrollo curricular, principalmente en el nivel de la educación primaria.

Al interior de la Universidad de Costa Rica la celebración del Congreso Universitario de 1972 y la promulgación en 1974 del nuevo Estatuto Orgánico inspirado en sus propuestas, representaron situaciones de interés inmediato al darse la oportunidad de fundamentar en el seno de la institucionalidad universitaria la propuesta de transformación organizativa de la Facultad de Educación. Al respecto, destaca la declaración de su artículo primero referido a la misión de la universidad dedicada a la docencia, la investigación, la acción social, el estudio, la meditación, la creación artística y la difusión del conocimiento. En este particular, desde los años iniciales de la década setenta se reiteran las interrelaciones entre esas tres funciones y, desde entonces, se integraron a la propuesta de transformación de la Facultad, siendo aún hoy parte esencial de su quehacer como centro formador de profesionales de la educación.

Se indicaba inicialmente la lista de facultades integradas por escuelas y por departamentos, nuestra Facultad estaba entre estas últimas según su organización interna que regía desde 1954, según se indicó anteriormente. En la versión del Estatuto Orgánico de 1990 (Universidad de Costa Rica, 1990), en su artículo 80, se señalan las facultades integradas con escuelas y ya aparece nuestra Facultad con las escuelas creadas entonces.

Se crearon las Áreas y se integró nuestra Facultad a la de Ciencias Sociales, correspondiéndole al autor del presente artículo, en su condición de decano, realizar su coordinación durante la elaboración, entrega, discusión y aprobación de la propuesta de transformación organizativa de la Facultad de Educación de los años setenta.

En el contexto internacional de la educación, en general, y del proceso de formación de profesionales en educación, particularmente, se derivaron también aspectos relevantes como antecedentes orientadores del proceso de cambio en de la estructura de la Facultad. En tal sentido se recuerda, en primera instancia, el "Proyecto Principal sobre Extensión y Mejoramiento de la Educación Primaria en América Latina” (UNESCO. 1956, citado por Arríen, 1996), con una duración de diez años. Como producto de este proyecto destacaron acciones de apoyo referidas a la alfabetización y la educación de personas adultas, la producción de libros de texto de bajo costo, el ataque al ausentismo escolar, la continuidad de las políticas educativas, el planeamiento sistemático de la educación, el estímulo a la creación de los institutos de investigación pedagógica, y el mejoramiento de los sistemas de formación profesional de docentes, entre otros temas de interés en ese momento histórico (Arríen, 1996).

Arríen (1996) señala que en las décadas de los años cincuenta y sesenta del siglo XX, en la región centroamericana fue importante el desarrollo de acciones en el contexto del Mercado Común Centroamericano, lo que incidía en las políticas y acciones educativas en general y, de manera específica, en la formación de profesionales de la educación, pues se daba un crecimiento alto de la población en edad escolar, 
sobre todo en zonas rurales, y había carencia de docentes, todo esto se realizaba enmarcado en la búsqueda de un modelo de integración regional.

Por otra parte, Arríen (1996) indica que temprano en los años setenta se ejecutó también un proyecto educativo de carácter internacional, el cual tuvo cierto grado de relación con nuestras actividades, fue el denominado Red de Sistemas Educativos para el Desarrollo en Centroamérica y Panamá (1975-1980). En este proyecto de desarrollo educativo se impulsaron acciones de cambio educativo y social en el marco de la integración subregional, siguiendo la premisa de que la educación es una variable interviniente e indicadora de desarrollo social. Este proyecto recibió el impulso de la UNESCO y contó con el apoyo y participación de los ministerios de educación de los países Centroamericanos, facilitó la búsqueda de soluciones a la problemática del desarrollo socio-económico y educativo del área, atacando los graves problemas estructurales que se reflejaban en el bajo desarrollo rural, bajos ingresos económicos de la población, subempleo, alto índice de analfabetismo, desigualdades en la distribución de oportunidades educativas, de vivienda, salud, cultura, etc. Desde el punto de vista educativo, se le recuerda porque promovió la aplicación de las investigaciones de tipo participativo (acción-reflexión-acción, diagnósticos socio-educativos, entre otros enfoques) y, conjuntamente con la UNICEF, se desarrollaban acciones educativas innovadoras, como fueron las carreras cortas y la capacitación laboral, la formación de personal administrador de la educación, la realización de diagnósticos participativos en el nivel comunitario, la nuclearización educativa y la formación permanente de personal docente para la educación básica.

Por último, en los años setenta fue importante la publicación, por parte de la UNESCO, del Informe de la Comisión Internacional de Educación, cuyo propósito fue el análisis y señalamiento de perspectivas para su desarrollo futuro en el mundo. En tal sentido, Faure et al. (1973), en calidad de coordinador del equipo de trabajo, señala los siguientes cuatro postulados básicos:

(1) A pesar de la diversidad de posiciones, políticas, tendencias de desarrollo, etc. existentes en los países, hay una comunidad de aspiraciones y de solidaridad fundamental entre los gobiernos y pueblos. (2) Existe una creencia en la democracia concebida como el derecho de cada persona a su plena realización y construcción de su propio destino. (3) El objetivo del desarrollo es el despliegue completo del hombre en toda su riqueza y en la complejidad de sus expresiones y compromisos como individuo, integrante de familias y colectividades y como ciudadano inventor de técnicas y creador de sueños. (4) La educación, como fuerza de creación de ese tipo de persona y ante las restricciones que le afectan, debe entenderse como un proceso global y permanente. No se trata solo de adquirir conocimientos sino de elaborar a lo largo de toda la vida un saber en constante evolución y de aprender a ser. (Faure et al., 1973, p. 16-17)

Años más tarde estos conceptos y perspectivas se reforzaron con los planteamientos del Informe de la UNESCO conocido como "La Educación Encierra un Tesoro" (Delors et. al, 1996), en el que se señalan los principios básicos de la educación para todas las personas y se consignan los cuatro pilares de la educación, a saber: "aprender a conocer", "aprender a hacer", "aprender a vivir juntos" y el relanzamiento del "aprender a ser" (p. 90-93). Estos cuatro pilares de la educación se fortalecieron luego al agregarse el de "aprender a emprender" junto con el concepto de que la educación se da a lo largo de la vida, como imperativo democrático y teniendo carácter pluridimensional al ser el centro de la sociedad" (Delors et al., 1996, p. 107-121).

En consecuencia, entre una y otra fuente de pensamiento, integrando criterios personales y profesionales emanados de la formación y experiencias de cada persona participante en el proceso de transformación, tanto en el nivel de dirección como en calidad de sujetos colaboradores integrantes de los equipos de trabajo, fue posible lograr, después de muchas horas de pensamiento, discusiones, acuerdos y desacuerdos, la elaboración consensuada de la nueva propuesta de estructura organizativa de la Facultad de Educación, lográndose finalmente su aprobación e implementación, como se seguidamente se explica. 


\section{Nueva estructura organizativa de la Facultad de Educación}

A continuación, se dan a conocer diversos aspectos que caracterizaron el proceso seguido en la elaboración, desarrollo, discusión, aprobación e implementación del proceso de transformación filosófica, administrativa y curricular de la Facultad de Educación, planteado originalmente para contar con cinco escuelas.

\subsection{Causas que motivaron la propuesta de una nueva estructura organizativa de la Facultad de Educación}

Una serie de hechos y circunstancias motivaron a las autoridades de la Facultad de Educación de los años setenta a llevar a cabo el proceso de cambio en su estructura organizativa, tomando en cuenta aspectos de tipo filosófico-pedagógico, administrativo y curricular, entre los que destacan los siguientes:

1. El modelo filosófico-pedagógico vigente desde la incorporación de la Facultad a la UCR, caracterizado por un fuerte acento en lo pedagógico y claramente pragmático e instrumentalista, a pesar de sus profundas raíces en el proceso de formación de personal educador que se realizaba en esa época y aunque se proyecta aún en años posteriores, demandaba una actualización a la luz de nuevas tendencias de pensamiento, movimientos mundiales en educación y cambios en los sistemas educativos al inicio de la década setenta.

2. Aspectos de tipo socio-económico y político de la sociedad costarricense, junto con las nuevas demandas de formación en campos de tipo técnico-profesional y tecnológico motivadas por cambios en el mundo del trabajo y en las relaciones de cooperación entre países de la región centroamericana y del mundo en general, también demandaban una visión distinta para el proceso de formación de profesionales de la educación.

3. Una visión de cambio se observaba también al darse un mayor acercamiento entre la educación considerada como ciencia y los aportes que a la pedagogía y, específicamente, al logro de una mejor conceptualización y comprensión de los procesos de enseñanza y aprendizaje, al que contribuyen otras ramas de las ciencias sociales (sociología, filosofía, psicología, antropología, etc.), así se llegó a la conceptualización de las ciencias de la educación con que se sustentó la nueva estructura organizativa propuesta para la Facultad de Educación, antepuesta al concepto tradicional vigente en periodos previos de una visión pedagógica del proceso educativo.

4. Entre el personal docente de la Facultad se intercambiaban ideas que poco a poco permeaban en la creación de nuevas formas de conocimiento y práctica favorables a la nueva estructura, inspiradas en el estudio de los aportes de Jean Piaget, L. Vigostky, Paulo Freire, Ausubel, J. Kozol, I. Illich, P. Goodman y M. Gadotti, entre otros pensadores conocidos en esos años. Durante los años setenta apenas se iniciaba el conocimiento de planteamientos que en tiempos posteriores serán de uso común entre profesionales de la educación, en campos como la epistemología educativa, nuevos enfoques sobre inteligencias múltiples, la aplicación de opciones distintas en cuanto a modelos y diseños de investigación y de evaluación educativa, el uso de nuevos recursos didácticos y de metodologías, técnicas y estrategias de enseñanza y aprendizaje, el lenguaje total, la mediación pedagógica y el constructivismo, entre otras corrientes educativas.

5. La estructura organizativa de la Facultad existente desde periodos previos dificultaba las interrelaciones profesionales y personales entre el personal docente, lo que se incrementaba al existir una relación desigual entre quienes pertenecían al régimen académico y quienes trabajaban de manera interina, con un claro predominio en cantidad de este segundo grupo de docentes. En consecuencia, la rigidez de la estructura junto con dificultades en los procedimientos académicoadministrativos presentaban trabas, entre otros aspectos, ante la necesidad de ejecutar los procesos 
para la selección y nombramiento en propiedad del profesorado, situación que a todas luces se debía cambiar para fortalecer a la institución.

6. Durante los primeros años de la década setenta, tanto por la incorporación al claustro docente de la Facultad de profesionales que se graduaron en el extranjero como por el estudio, conocimiento y experiencias de quienes ejercían labores docentes en ese tiempo, era posible compartir ideas orientadas hacia la necesidad de cambio, por ejemplo, la búsqueda de mayor participación estudiantil, el logro de mejores grados en la relación docente-estudiante, el impulso a la investigación educativa, la modernización de los procesos metodológicos y de evaluación de los aprendizajes, la actualización de estrategias, técnicas y recursos utilizados en la didáctica y práctica docente (práctica o experiencia profesional); la reflexión sobre mejores técnicas y estrategias aplicadas en la docencia universitaria, la integración de diferentes temas curriculares (perfiles académicos, de ingreso y finales de las carreras), planteamiento de objetivos de aprendizaje en los cursos, transversalidad y el cambio del foco de la enseñanza hacia el aprendizaje.

7. En los años setenta se consideró necesario, y finalmente se logró, proyectar cada vez con mayor insistencia las acciones de la Facultad de Educación hacia el interior de la Universidad de Costa Rica, así como sus relaciones externas. Se tomaron en cuenta sus relaciones de apoyo, coordinación y proyección hacia el Consejo Superior de Educación, el Ministerio de Educación Pública, el Instituto Nacional de Aprendizaje (INA) y las organizaciones magisteriales existentes (ANDE, APSE y COLYPRO). Se reforzaron las acciones de enlace y cooperación con otras instituciones de reciente creación en el nivel de educación superior, como lo fueron el Instituto Tecnológico de Costa Rica y la Universidad Nacional. De igual manera se consideró la necesidad de establecer coordinaciones con organismos internacionales (UNESCO y UNICEF, por ejemplo).

8. La estructura organizativa de la Facultad de Educación anteriormente vigente, basada en departamentos, secciones y carreras, resultaba ineficiente y hasta obsoleta ante su crecimiento financiero-presupuestario, administrativo y académico-curricular de la Facultad, junto con el alto número de estudiantes, del personal docente y administrativo cuyas demandas e inquietudes debían atenderse y resolverse desde el decanato y sus escasas instancias de apoyo, como únicas vías de canalización existentes.

9. Una causa importante se dio en consonancia con los cambios institucionales que al interior de la Universidad de Costa Rica se introdujeron como consecuencia de los acuerdos y recomendación del Congreso Universitario de 1972 y la promulgación y entrada en vigencia del nuevo Estatuto Orgánico (1974), en particular la nueva forma de integración del Consejo Universitario, según la cual quienes ejercieran los puestos de decanato no formarían parte de este, el establecimiento de las áreas, la creación de las facultades integradas por escuelas y, desde luego, las funciones de docencia, investigación y acción social como fundamento de la misión de la Universidad.

10. La conformación que tenía el personal de la Facultad en abril de 1975, cuando contaba con 31 personas laborando en tareas administrativas y 152 realizando labores docentes, motivaba la necesidad de fortalecer el claustro, razón que también se tomó en cuenta en la gestión de la nueva estructura. Esta situación se muestra en la tabla 1.

11. Como complemento de la causa anterior, en el mes de mayo de 1975, la Facultad ofrecía 31 carreras, 114 cursos y un total de 182 grupos, contando con 4882 estudiantes, incluyendo a quienes seguían carreras de Profesorado en Segunda Enseñanza, o sea, compartidos con las diferentes Unidades Académicas responsables de su formación en cada área especializada (ciencias, matemática, inglés, música, psicología, historia y geografía, etc.). Esta situación se presenta en la tabla 2 según su distribución por Escuelas y según la distribución que se hiciera para justificar la propuesta de la nueva estructura de la Facultad integrada con cinco escuelas. 
12. La necesidad de impulsar la acción social en la Facultad actuó también como otra causa motivadora del cambio de su estructura organizativa en los años setenta. En ese tiempo se realizaban actividades dirigidas a otras instancias universitarias, principalmente de tipo didáctico, y se hacía un trabajo de apoyo en acciones de capacitación docente en apoyo al Ministerio de Educación Pública y los gremios magisteriales. En la propuesta de nueva estructura se consideró necesario ampliar las acciones de proyección de la Facultad en el marco de los nuevos planteamientos de esta función universitaria.

En tal sentido, durante el proceso de cambio seguido se hizo un trabajo intenso para fortalecer las relaciones interinstitucionales, creando nuevas opciones de relación hacia el exterior de la Facultad -exoestructura-. Así, se gestionaron proyectos nuevos de acción social y se establecieron nexos de coordinación y apoyo mutuo, mediante alianzas estratégicas, con las organizaciones magisteriales existentes (ANDE, APSE, SEC, COLYPRO), con el Consejo Superior de Educación, el Ministerio de Educación Pública y el INA, entre otras instituciones educativas.

Como hecho significativo se recuerda el plan integral de capacitación que se implementó en Liberia, Guanacaste, en el área de las Artes Industriales y en el nivel de Educación Primaria en el cual se llegó, entre 1970 y 1977, a la graduación de cientos de personas educadoras con distintos tipos de certificaciones, lo que les favorecía salarialmente y en ascensos según las categorías y grupos de la Ley de Carrera Docente y el Estatuto del Servicio Civil Docente. Estas acciones, en cierta forma, sirvieron de base y orientación para la creación posterior del Centro Universitario Regional de la Universidad Costa Rica en ese lugar.

En coordinación con los gremios de educadores y el MEP se realizaron múltiples misiones de trabajo en distintas regiones del país, entre otras áreas académicas en inglés, estudios sociales, ciencias naturales y en evaluación educativa. De igual manera, se desarrollaron e implementaron distintos planes de formación de docentes en servicio en la sede central y en otras instancias institucionales, en especialidades tales como Educación para el Hogar, la Educación Familiar y Social, Evaluación Educativa, Didáctica en distintas especialidades, etc. Se llegó, inclusive, a trabajar los fines de semana, y se fortaleció la proyección de la Facultad de Educación en el sistema educativo del país; además, se logró un mayor reconocimiento por su cercanía en la atención y respuesta efectiva a problemas nacionales y del cuerpo docente.

TABLA 1

Personal docente de la Facultad de Educación. Abril de 1975

\begin{tabular}{lll}
\hline Categoría & Cantidad Absoluta & Porcentaje \\
\hline 1.Horas estudiante & 2 & 1,32 \\
2.Asistentes & 37 & 24,34 \\
3.Profesores de Horas (I Semestre) & 46 & 30,26 \\
4. Profesores de Cátedra Anual & 7 & 4,60 \\
5. Profesores de 1/4 de Tiempo & 10 & 6,57 \\
6. Profesores de 1/2 de Tiempo & 24 & 15,79 \\
7. Profesores de $3 / 4$ de Tiempo & 1 & 0,66 \\
8. Profesores de Dedicación Exclusiva & 1 & 0,66 \\
9. Profesores de Tiempo completo & 22 & 14,47 \\
10. Profesores ad-honorem & 2 & 1,32 \\
Total & 152 & 100 \\
\hline
\end{tabular}

Nota: Tomado de Ugalde (1975, p. 86-88). 
TABLA 2

Distribución de las ofertas académicas de la Facultad de Educación, según la propuesta de nueva estructura organizativa. Mayo de 1975

\begin{tabular}{lllll}
\hline Escuelas & Carreras & Cursos & Grupos & Estudiantes \\
\hline 1.Administración Educativa & 1 & 16 & 53 & 1.425 \\
2. Formación Docente & 22 & 38 & 48 & 1.407 \\
3. Psicopedagogía & 5 & 21 & 39 & 1.403 \\
4. Bibliotecología & 2 & 10 & 13 & 307 \\
5. Educación Física & 1 & 29 & 29 & 340 \\
\hline Total & 31 & 114 & 182 & 4.882 \\
\hline
\end{tabular}

Nota: El nombre de Escuela de Psicopedagogía, propuesto inicialmente, se aprobó como Escuela de Orientación y Educación Especial, tal y como se le conoce actualmente. Tomado de Ugalde (1975, p. 89).

\subsection{Criterios aplicados y participación en el proceso de gestación de la nueva estructura organizativa}

Seguidamente se presentan los criterios utilizados para organizar las distintas áreas de trabajo de la Facultad según su nueva estructura organizativa en escuelas:

- Establecer un mayor nivel de homogeneidad entre las carreras, cursos y demás servicios a cargo de cada nueva escuela y sus subdivisiones, integrando cursos y actividades afines, para fortalecer, de esta manera, las relaciones profesionales y la interacción humana entre el personal participante.

- Agilizar y flexibilizar la oferta de cursos y servicios de apoyo a cargo de la Facultad con el propósito de atender, de manera más efectiva, las demandas del estudiantado, del personal docente y administrativo y de los educadores y educadoras en servicio. De esta manera se procuró superar los problemas que se acarreaban con la anterior estructura basada en departamentos, secciones y carreras.

- Introducir niveles intermedios de mando, coordinación y toma de decisiones, creando instancias que ofrecieran tanto posibilidades de participación y ascenso como opciones de nuevos liderazgos (direcciones y subdirecciones de Escuela, direcciones y subdirecciones de Departamentos, coordinaciones de secciones, entre otros).

- Descentralizar, administrativa y financieramente, el accionar de la Facultad de Educación, dado que hasta ese momento estas funciones dependían de la dirección y control de quien ejerciera el Decanato, lo que producía restricciones por un lado y recargo de funciones por otro.

- Crear mejores condiciones para incentivar la participación e identificación de estudiantes con sus nuevas unidades académicas, cada una con sus alcances específicos, en función de sus intereses y procurando el logro de mayor impacto a la luz de las inquietudes de su quehacer académico.

- Darle mayor especificidad y prontitud a la tramitología de procesos administrativos relacionados con la vida estudiantil (matrícula, orientación, guía, selección de carreras, procesos de admisión y de graduación, etc.) y con los procesos de ingreso de docentes al régimen académico.

Aunque en primera instancia el cambio propuesto aparentaba ser relativamente sencillo por tratarse del tránsito de una organización con varios departamentos, secciones y carreras hacia una Facultad integrada con Escuelas; en la realidad no resultó tan fácil seguir el proceso completo de transformación desde la gestación de la propuesta y la elaboración de documentos básicos pasando por su presentación, discusión y análisis, tanto en el Consejo Asesor de la Facultad y en la misma Asamblea de Facultad, como en otras instancias universitarias (Área de Ciencias Sociales, Consejo Universitario y Asamblea Universitaria). Fue necesario invertir tiempo y recursos humanos, bajo la forma de horas de mucho trabajo, esfuerzo y dedicación para crear las condiciones que facilitaran las discusiones y abrieran el camino para la aprobación final de la propuesta. 
La oposición no se hizo esperar, pues prácticamente durante la mayor parte del proceso seguido, se tuvo que enfrentar infinidad de retos y vencer barreras tanto al interior de la Facultad, por la oposición de una parte del profesorado especialmente pertenecientes a generaciones previas, como en otras instancias universitarias, en especial al nivel de toma de decisiones.

Dichosamente se contó desde los primeros pasos del proceso con un equipo de trabajo muy positivo, altamente motivado y convencido de la necesidad de llevar a cabo la transformación de la estructura organizativa de la Facultad. Las múltiples reuniones tuvieron lugar en la soda, en las aulas, pasillos, oficinas y hasta en los hogares de colegas y amistades.

Con temor a olvidar algunos nombres y con las disculpas del caso, se identifican los siguientes colegas de la época, quienes acompañaron al Decano y apoyaron con determinación y esfuerzo todo el proceso de cambio. Como equipo central el decano contó con el apoyo incondicional y la participación de Yolanda Rojas R., Moisés Befeler T., Flor de María Pérez Zamora, Dalia Edelman y Fernando Castro Ramírez. Además, colaboraron directa o indirectamente, Angelina Abarca Molina, Clarence Binns Mowat, Raymon Anglin Edwards, Lydia Somarribas Chavarría, Jeffry Hutchinson Da Costa, Elia María Van Patten Ugalde, Lisbeth Fallas Jiménez, Eduardo Ávalos Chinchilla, Mario Fernández Lobo, Carlos Alberto Calvo Zúñiga, Humberto Pérez Pancorbo, Sigifredo Sancho Benito, Miriam García Charpantier, Fernando Villalobos Solé, Alfredo Calvo Hernández, Lidiette Diez Solano, Benilda Salas, Ana Cecilia Hernández Rodríguez, Carlos Moya Barahona, Rodrigo Pacheco López, Sandra García Pérez, Jorge Muñoz Guillén y otros docentes, quienes junto con el apoyo de la Asociación de Estudiantes de Educación y miembros del personal administrativo hicieron posible el logro de la nueva estructura organizativa de la Facultad integrada con cinco Escuelas. Una lista completa de participantes se tiene en el Informe de Labores del Decanto de los años 1974-1975 (Ugalde, 1975).

\subsection{Organización de la nueva estructura propuesta para la Facultad integrada con cinco Escuelas}

Ugalde (1974), en el documento para Sesión del Consejo Asesor Ampliado de la Facultad de Educación, informa sobre la propuesta de estructura conformada por cinco Escuelas, con un total de 27 unidades de servicios propuesta en ese año, lo que luego llegó a aprobarse en 1977 como tres Escuelas y los correspondientes Departamentos y Secciones, cuando la Facultad ofrecía 34 carreras con sus correspondientes planes de estudio. Dicha propuesta se resume así:

1. Escuela de Administración Educativa, con cuatro servicios: Administración Educativa, Investigación Educativa, Tecnología Educativa y Socio-Filosofía Educativa.

2. Escuela de Formación Docente, con 14 servicios: Currículum, Educación Técnica, Enseñanza de la Educación Física, Enseñanza de la Educción Inicial y Básica, Enseñanza de la Educación Especial, Enseñanza de la Filosofía, Enseñanza de Lenguas Modernas, Enseñanza de Psicología, Enseñanza de Ciencias, Enseñanza de Estudios Sociales, Enseñanza de Español, Enseñanza de Matemática, Enseñanza de Educación Artística y Enseñanza de Bibliotecología.

3. Escuela de Psicopedagogía, que se aprobó como Escuela de Orientación y Educación Especial, con tres servicios: Psicología Educativa, Orientación y Educación Especial.

4. Escuela de Bibliotecología, con tres servicios: Fundamentos de Bibliotecología, Técnicas Bibliotecarias y Servicios Bibliotecarios Especializados.

5. Escuela de Educación Física, con tres servicios: Fundamentos Científicos de la Educación Física, Deportes y Gimnasia y Recreación. (Ugalde, 1974, p. 22) 
En el documento inicial sobre la propuesta de nueva estructura organizativa se dieron a conocer también los fines de las funciones de docencia, investigación y acción social, que orientarían el accionar de la Facultad de Educación, basándose para ello en los preceptos del nuevo Estatuto Orgánico de la Universidad de Costa Rica, de 1974. En síntesis se indicó lo siguiente:

A) Acción Social: La Facultad establece como principio su compromiso con la problemática de la realidad costarricense, ofreciendo tanto para los estudiantes como para los profesores oportunidades efectivas para: a) Propiciar el desarrollo de una sensibilidad social correspondiente a las necesidades del país. b) Participar y colaborar en la resolución de problemas de las comunidades nacionales.

B) Investigación: La investigación es el fundamento de la docencia y de la acción social, la Facultad de Educación en cuanto a este campo se refiere dará, tanto a profesores como a estudiantes, oportunidades efectivas para: a) Facilitar y orientar las labores de docencia y de acción social, el mejoramiento docente del personal y el desarrollo de una actitud de investigación y experimentación. b) Promover el estudio de los aspectos esenciales y técnicas de la investigación educativa, así como la ejecución de proyectos de investigación.

C) Docencia: "Cada Escuela brindará, en cuanto a docencia se refiere, oportunidades para que los estudiantes, con la guía de sus profesores, en el campo respectivo: a) Comprendan los aspectos esenciales. b) Apliquen los principios fundamentales y métodos. c) Interpreten las necesidades y aspiraciones de su ambiente. d) Analicen las diversas tendencias que se presenten. Además, procurará que los estudiantes: e) Comprendan su labor como profesionales docentes, sus responsabilidades y derechos. f) Desarrollen una actitud de investigación y experimentación. g) Promuevan un ambiente orientado hacia valores humanísticos y h) Desarrollen destrezas de comunicación interpersonal e intergrupal” (Ugalde, 1975. p. 20-21).

Ugalde (1975), en su Informe de Labores del Decanato 1974-1975, señala que en la propuesta de nueva estructura para la Facultad se tomaron en cuenta sus relaciones hacia otras instancias universitarias (Consejo Universitario, Áreas, otras Unidades Académicas, Vicerrectorías, Oficina de Régimen Académico, Comisiones Coordinadoras, etc.) y hacia instancias nacionales e internacionales (Consejo Superior de Educación, Ministerio de Educación Pública, gremios magisteriales, centros educativos, comunidades, organismos internacionales, medios de comunicación social, etc.), lo que, en su conjunto, conformaba la exoestructura de la Facultad.

En setiembre de 1974 el Consejo Coordinador del Área de Ciencias Sociales aprobó esta propuesta de estructura para la Facultad, integrada con cinco Escuelas, y la pasó al Concejo Universitario y este organismo, tres años después, el 21 de febrero de 1977, según el Acuerdo N.o 8 de su sesión N.o 2356, aprobó la estructura de organizativa de la Facultad de Educación integrada con tres Escuelas, en la siguiente forma:

En consecuencia, se acuerda:

a) Aprobar la nueva estructura de la Facultad de Educación, la cual consiste en la división de la actual unidad en tres Escuelas a saber: Escuela de Administración Educativa, Escuela de Orientación y Educación Especial. Escuela de Formación Docente (la cual contiene, además de sus carreras, el Departamento de Educación Física y el Departamento de Docencia Universitaria).

b) Posponer la evaluación de la Facultad de Educación que el Consejo Universitario acordó se efectuase previamente a la aprobación de la nueva estructura.

c) Posponer para el segundo año de funcionamiento de la nueva estructura la decisión sobre el cambio de ubicación del Departamento de Docencia Universitaria y de la carrera de Bibliotecología. Los integrantes de esas unidades proponen que se adscriban al Decanato. 
d) Que la Facultad debe incluir a los Departamentos de Educación Física y Docencia Universitaria en la descripción de la Escuela de Formación Docente del plan de la nueva estructura pues solamente aparecen en el organigrama. (Universidad de Costa Rica, 1977, p. 1)

La Asamblea Colegiada Representativa, en sesión del 12 de mayo de 1977, aprobó definitivamente la modificación del Artículo 80 del Estatuto Orgánico, y dio así a la Facultad de Educación la condición de estar integrada por tres Escuelas: Administración Educativa, Formación Docente y Orientación y Educación Especial. La propuesta de la Escuela de Bibliotecología y Ciencias de la Información se aceptó entonces como Sección de la Escuela de Administración Educativa y la Escuela de Educación Física y Deportes como Departamento de la Escuela de Formación Docente.

La estructura organizativa propuesta que se aprobó en dicha fecha con base en la integración de escuelas y estas subdivididas en departamentos y secciones se resume seguidamente:

1. Escuela de Administración Educativa con cuatro Secciones: Administración Educativa, Bibliotecología y Ciencias de la Información y Socio-Filosofía Educativa y Tecnología Educativa.

2. Escuela de Formación Docente con dos Departamentos cada uno subdividido en Secciones, así: Educación Física y Deportes, con dos Secciones de Actividad Deportiva y Enseñanza de Educación Física; y Docencia Universitaria, con tres Secciones: Currículum, Didáctica e Investigación. Además de cuatro Secciones, a saber: Educación Técnica, Currículum y Experiencia Profesional, Educación Preescolar y Primaria y Capacitación En esta Sección se proponía atender los campos de la Educación Técnica Industrial y Agropecuaria, Artes Plásticas y Artes Industriales, Retardo Mental, Educación Familiar y Social y Educación para el Hogar y Educación Sexual.

3. Escuela de Orientación y Educación Especial con tres Secciones: Orientación, Educación Especial y Psicología Educativa.

Desde agosto de 1977 la Facultad organiza oficialmente sus ofertas académicas con esta estructura, la cual se reforzó en 1989 al aceptar el Consejo Universitario la creación de las dos Escuelas que habían quedado pendientes (Bibliotecología y Ciencias de la Información y Educación Física y Deportes), aunque internamente se había hecho una distribución tentativa de las mismos desde años previos anticipándose a su aprobación final.

Efectivamente, en lo que a la Escuela de Educación Física y Deportes se refiere, según la Gaceta N.o 22-1989, del 16 de agosto de 1989 (Universidad de Costa Rica, 1989 Universidad de Costa Rica, 1989), el Decano de la Facultad, en funciones de Coordinador del Consejo del Área de Ciencias Sociales, eleva nuevamente al Consejo Universitario la gestión de aprobación de esta Escuela con el nombre de "Escuela de Movimiento Humano y la Recreación”. El Consejo Universitario, con fecha del 29 de agosto de 1989, remite esta gestión a estudio y dictamen de la Comisión de Política Académica, la que se pronuncia el 13 de setiembre de 1989, según la Gaceta N.o 25-1989, y el Consejo Universitario acuerda, con igual fecha, la transformación del Departamento de Educación Física y Deportes en Escuela, conservando este nombre (Universidad de Costa Rica, 1989).

El camino seguido por el Departamento de Bibliotecología y Ciencias de la Información, el cual existía desde 1968 aunque como carrera universitaria vinculada a la Facultad y a la Biblioteca de la UCR, tomó igual lapso, pues su transformación en Escuela tuvo lugar por acuerdo del Consejo Universitario en 1989. Con esto se completa la integración de la Facultad de Educación con sus cinco Escuelas. En ese momento la nueva Escuela impartía dos énfasis: Bibliotecas Educativas y Ciencias de la Información. De las secciones inicialmente planteadas, gracias a su propia evolución y aportes de sus profesionales docentes que se incorporaron después de realizar estudios en el país y en el extranjero, se ha fortalecido de manera que con el tiempo ha ido ampliando y mejorando sus servicios (Universidad de Costa Rica y Escuela de Bibliotecología y Ciencias de la Información, 2016). 
En 1977 la Facultad ofrecía un total de 20 carreras en el nivel de Bachillerato Universitario y cinco de Licenciatura, así:

- Bachilleratos Universitarios: Bachillerato en Ciencias de la Educación Preescolar; Bachillerato en Ciencias de la Educación Primaria con cuatro Énfasis: Ciencias, Estudios Sociales, Artes del Idioma y Matemáticas; Bachillerato en Educación Especial con tres Énfasis: Trastornos de la Comunicación, Retardo Mental y Problemas de Aprendizaje; Bachillerato en Ciencias de la Educación con Énfasis en Orientación; Bachillerato en Ciencia de la Educación con Énfasis en Bibliotecología y Bachilleratos en la Enseñanza de Artes Industriales, Artes Plásticas, Artes Dramáticas, Ciencias Generales, Biología, Química, Física, Castellano y Literatura, Estudios Sociales (Historia y Geografía), Educación Física, Filosofía, Francés, Inglés, Matemática, Música y Psicología.

- Licenciaturas: Licenciatura en Ciencias de la Educación con Énfasis en Orientación; Licenciatura en Ciencias de la Educación con Énfasis en Administración Educativa; Licenciatura en Ciencias de la Educación con Énfasis en la Enseñanza de la Matemática y Licenciatura en Bibliotecología y Ciencias de la Información.

En 1978 se propuso la creación de cuatro nuevas carreras en el nivel de Licenciatura en la Enseñanza de la Educación Física, en Educación Preescolar y en Educación Especial con Énfasis en Trastornos Visuales y en Educación Especial con Énfasis en Trastornos Emocionales. Además, como se indicó previamente, ya se gestaba también la oferta de carreras en el nivel de posgrado (Maestría y Doctorado en Educación), lo que se plasma en realidad años más tarde.

Ugalde (1978) menciona que en 1978, cuando se experimentaba apenas un año de la aprobación y vigencia de la nueva estructura organizativa, la Facultad tenía un total de 160 docentes, de este grupo 73 pertenecían a Régimen Académico (45\%). Entre este personal se tenían seis Catedráticos y Catedráticas (4,4\%), 21 en la categoría de Profesorado Asociado (13,1), 13 en la de Profesorado Adjunto (8,1\%) y 33 Instructores e Instructoras (20,5\%). El resto era personal interino (55\%). Esta situación dificultaba los procesos internos de discusión, análisis y toma de decisiones sobre las acciones de cambio que demandaba la nueva estructura (p. 13).

En cuanto al uso de las instalaciones físicas, al pasar a tener tres nuevas Escuelas y dos Departamentos, en el seno del Consejo Asesor de Facultad se acordó ubicar a la Escuela de Administración Educativa en el primer piso, a la Escuela de Orientación y Educación Especial en el segundo piso y a la Escuela de Formación Docente en el tercer piso, el que para entonces se había construido gracias al apoyo de la Oficina de Planificación Universitaria (OPLAU) entonces existente. El Departamento de Bibliotecología y Ciencias de la Información se ubicó en el edificio de Artes Industriales junto con parte del personal docente de las Secciones de Educación Preescolar y Educación Técnica, y el Departamento de Educación Física y Deportes se ubicó en las instalaciones deportivas de la Universidad de Costa Rica, en Sabanilla de Montes de Oca. Esta distribución de espacios físicos en general se conserva actualmente, salvo contadas excepciones debido a remodelaciones, nuevas construcciones y ajustes necesarios ante el establecimiento de nuevas instancias de trabajo en la Facultad de Educación.

\subsection{Elementos del proceso de discusión y aprobación de la nueva estructura organizativa}

Durante el proceso de elaboración, desarrollo, estudio, aprobación e implementación de la nueva estructura, se vivieron momentos de mucha tensión, situaciones que repercutieron intensamente, pues a pesar de que desde el inicio se contó con el apoyo de una mayoría del personal interino y administrativo, no se dio la misma situación con parte del personal docente en propiedad; haciéndose muy difícil la tarea para lograr 
su convencimiento y la aceptación de la propuesta, especialmente de quienes trabajaban en la Facultad de Educación desde los periodos previos.

Aunque hoy puedan verse como elementos anecdóticos, se recuerdan algunos detalles que caracterizaron el proceso seguido durante la presentación, discusión y aprobación final de la nueva estructura ante las distintas instancias universitarias. Las circunstancias que se describen reflejan una vez más las dificultades que generalmente enfrenta esta Facultad de Educación cuando lleva a cabo alguna gestión de cambio, situación que vivió con su incorporación a la Universidad de Costa Rica en 1941, en la Reforma de los años de 1954 a 1957 y durante la gestión y aprobación de la nueva estructura durante los años setenta.

Las primeras discusiones y enfrentamientos entre integrantes del cuerpo docente tuvieron lugar en el seno de la Asamblea de Facultad, motivadas por las diferencias de formación académica, pedagógica y filosófica existentes entre dicho personal, así como por las diferencias de criterios y experiencias que les caracterizaban. Además, se presentaban diferencias en función del lugar y la instancia universitaria en que se formaron unos individuos y otros, incluyendo a quienes se habían graduado de la misma Universidad de Costa Rica, al lado de otros grupos docentes de la Facultad que estudiaron en universidades de los Estados Unidos, Puerto Rico, México y de países europeos y suramericanos.

$\mathrm{Al}$ interior de los equipos de trabajo y en las instancias de discusión en otros niveles universitarios surgían opiniones distintas y se manifestaban actitudes de aceptación o rechazo según fuera la condición académica de cada docente, esto es, si pertenecían o no a Régimen Académico, pues se daba un trato diferenciado al personal interino al enfrentarse al personal en propiedad, lo que ameritaba atención especial de la Decanatura y de integrantes del equipo principal.

Una vez aprobada la propuesta inicial al interior de la Facultad (Consejo Asesor y Asamblea de Facultad), se debía pasar al Consejo de Área de Ciencias Sociales, en donde las diferentes posiciones se daban por tener la Facultad la responsabilidad de los cursos pedagógicos de las carreras de Profesorado de Segunda Enseñanza, lo que se acarreaba como máxima dificultad desde la Reforma de 1957. No obstante, el hecho de que el decano fuera el coordinador de dicha Área en ese tiempo y contando con el apoyo de estimables colegas de otras decanaturas de otras facultades universitarias, se pasó con éxito este nivel de análisis y aprobación.

Otras dificultades surgieron en el seno del Consejo Universitario, al no considerar la necesidad y perspectiva de la propuesta de nueva estructura. Después de la realización de varias sesiones de presentación, estudio y discusión de la propuesta, esta instancia nombró una Comisión Especial para que estudiara y dictaminara lo que mejor correspondiera. El Dr. Manuel María Murillo, la Dra. Hilda Chen Apuy y el Lic. Eduardo Fournier integraron dicha comisión y, lastimosamente, según carta que dirigieran al Dr. Sherman Thomas, director del Consejo Universitario el 22 de febrero de 1975, su dictamen fue negativo, pues hicieron caso omiso de nuestra propuesta de cambio y, sin mayores consideraciones, sugirieron que la Facultad se dividiera en tres Departamentos, a saber: Ciencia y Tecnología Educativa, Bibliotecología y Educación Física, lo que evidentemente iba en contra y menoscabo de la propuesta (Ugalde, 1975).

Dichosamente esa situación tuvo un efecto positivo en el seno de la Facultad, pues se evidenció el poco interés que había en atender nuestra gestión, a pesar de que el Consejo Universitario ya había aceptado, desde antes de 1974, la integración de otras Facultades en Escuelas (Tres en Bellas Artes, cinco en Ciencias Económicas y cinco en Ingeniería). Como consecuencia, se dio un hecho interesante al interior de la Facultad: se produjo mayor integración de opiniones e intereses como producto del resentimiento y el enojo, lo que hizo posible llevar a cabo una Asamblea de Facultad en la cual se contó con la presencia del Dr. Claudio Gutiérrez, rector, de la cual salió el acuerdo unánime en apoyo a la gestión de la nueva estructura en los términos y condiciones que interesaban e impulsaba la Facultad. El resto del proceso se dio con fluidez hasta alcanzar exitosamente el propósito esperado y en la forma que se explica en el presente artículo. 


\section{Conclusiones}

Seguidamente se anota una serie de conclusiones derivadas del análisis realizado destacando, en función de los objetivos propuestos, los puntos fundamentales que caracterizaron el proceso de gestión, elaboración, estudio, aprobación e implementación de la nueva estructura organizativa de la Facultad de Educación.

a) El proceso seguido para el logro de la nueva estructura de la Facultad de Educación integrada con cinco Escuelas se realizó con determinación, en un contexto de abierta participación, de manera organizada, sistemática y aplicando reglamentación universitaria existente. Las etapas seguidas tomaron en cuenta los elementos considerados como los más apropiados desde la gestión de la idea, hasta llegar a la elaboración de documentos, su presentación, estudio, aprobación e implementación de la nueva estructura. No obstante, se reconoce que también se presentaron momentos críticos que debieron enfrentarse con mucha firmeza y decisión para lograr superarlos.

b) En una primera instancia y después de casi tres años de lucha, el 21 de junio de 1977, se logró la aprobación de las primeras tres de las cinco Escuelas propuestas (Administración Educativa, Formación Docente y Orientación y Educación Especial), por parte del Consejo Universitario y el 12 de mayo de 1977 por parte de la Asamblea Colegiada Representativa, la creación de las Escuelas de Bibliotecología y Ciencias de la Información y la Escuela de Educación Física y Deportes se postergó para años más tarde, hasta que en 1989 se crearon ambas.

c) La base conceptual de la propuesta de la nueva estructura de la Facultad se sustentó en la conjugación de tres líneas de pensamiento y acción, según elementos filosófico-pedagógicos, administrativos y curriculares, con lo cual se respaldó la elaboración de los documentos y el seguimiento dado al proceso de presentación y análisis correspondientes.

d) Los aspectos de tipo filosófico y pedagógico se inspiraron en el estudio de los valiosos aportes de distinguidos educadores y distinguidas educadoras del país, de la Universidad de Costa Rica y de la misma Facultad, quienes ejercieran posiciones reconocidas de liderazgo, gestión, organización y toma de decisiones. En especial se consideraron los valiosos aportes del pensamiento y las experiencias de las exdecanas Dra. Emma Gamboa A. y la Licda. María Eugenia Dengo O., junto con los aportes de sus mentores, en el país y en el extranjero, además de sus propias experiencias personales y profesionales, siempre respetadas y reconocidas en los ámbitos educativo, social y político. Prevaleció la concepción de las ciencias de la educación, gracias a los aportes de las personas profesionales de la educación consultadas y el pensamiento aportado por el personal profesional propio de la Facultad.

e) De las distinguidas exdecanas se rescataron sus planeamientos de respeto a la dignidad humana, solidaridad, participación y sentido organizativo, junto a su valor, identificación institucional y entrega en las luchas a favor de la defensa y el fortalecimiento de la Facultad de Educación. Ambas propiciaron la formación integral del ser humano con sentido político-social, inspiradas en las tendencias filosóficas y pedagógicas de la época según movimientos propios del pragmatismo estructural, pero con una nueva visión humanista.

f) Desde las dimensiones administrativa y curricular se buscó el fortalecimiento financieropresupuestario de la Facultad, junto con una visión integrada de los servicios de índole académico, profesional y curricular que llegaría a ofrecerse con la nueva estructura. De aquí el concepto básico de la propuesta basado en la creación de cinco Escuelas integradas en una Facultad y nunca de una Facultad dividida en cinco Escuelas. Las ofertas curriculares de carreras y cursos se organizaron de manera homogénea, procurando poner juntas, de manera interrelacionada e integrada, las ofertas de formación de profesionales de la educación que fueran similares o complementarias, se fortaleció la relación personal y profesional entre docentes y se propició una mayor participación del estudiantado. 
g) $\mathrm{Al}$ proceder de esa manera se buscaba crear mayores y mejores nexos de relación entre el personal docente de la Facultad, lo mismo que crear opciones para la competencia que facilitara el mejoramiento del desempeño profesional, entonces sometido a fuertes críticas, y el surgimiento de nuevos liderazgos, de los que tanto carecía la Facultad dividida en departamentos, secciones y carreras heredada de los periodos previos. Con la nueva estructura se crearon nuevos puestos académicos y administrativos que favorecieron la superación profesional y personal, lo que facilitó el acceso a estos mismos, por ejemplo, los puestos en el Decanato, las Direcciones de Escuela, de Departamentos, de Centros o Institutos, las Coordinaciones de Secciones; lo mismo que una diversidad de puestos en el campo administrativo de apoyo.

h) Por último, es importante reconocer el valor institucional de la nueva estructura organizativa de la Facultad de Educación integrada con cinco Escuelas, tanto por su concepción y desarrollo histórico como porque aún en la actualidad, después de casi cuarenta años después de su aprobación, sigue vigente, mejorada, ampliada y fortalecida en la organización interna de cada una de sus Escuelas y en la Facultad como un todo integrado y armónico; crece con nuevos Centros e Institutos, Escuela y Liceo Laboratorio, recursos tecnológicos nuevos, medios de divulgación y aplicando , progresivamente, nuevas opciones curriculares en los niveles de grado y posgrado, fortaleciendo las labores de investigación educativa y de acción social, cuyo conjunto de acciones le brindan una nueva visión y proyección en la Universidad, en el nivel nacional e internacional y, de manera específica, en el mantenimiento de su liderazgo en el campo de la formación de profesionales de la educación en el país.

\section{ReFERENCIAS}

Arríen, J. B. (1996). UNESCO en el desarrollo y en las innovaciones de la educación en Centroamérica. San José, Costa Rica: Oficina de la UNESCO para Centroamérica y Panamá.

Delors, J., Al Mufti, I., Amagi, I., Carneiro, R., Chung, F., Geremek, B., ... Nanzhao, Z. (1996). La educación encierra un tesoro. México: Correo de la UNESCO.

Dengo O., M. E. (2011). Tierra de maestros. San José, Costa Rica: Editorial UCR.

Faure, E., Herrera, F., Lopes, H., Pétrovski, A. V., Rahnema, M. y Champion W. F. (1973). Aprender a ser. UNESCO: Alianza Editorial.

Ministerio de Educación Pública (MEP). (1973). Plan nacional de desarrollo educativo. Decreto N.o 3333-E. San José, Costa Rica: Autor.

República de Costa Rica. Asamblea Legislativa. (1957). Ley N.o 2160. Ley Fundamental de Educación. San José, Costa Rica: Autor.

República de Costa Rica. Asamblea Legislativa. (1972). Ley Orgánica N.o 4770 del Colegio de Licenciados y Profesores en Letras, Filosofía, Ciencias y Artes. San José, Costa Rica: La Gaceta N.o 205.

República de Costa Rica. Asamblea Legislativa. (1977). Estatuto de Servicio Civil. (Ley N.o 1581 de 30 de mayo de 1953). Su reglamento (Decreto Ejecutivo N.o 21 de 14 de diciembre de 1954) y otras leyes conexas. San José, Costa Rica: Imprenta Nacional.

República de Costa Rica. Asamblea Legislativa. (1970). Ley N.o 4565 Adición a la Ley N.o 1581 del 30 de mayo de 1953 (Estatuto de Servicio civil) Título II Ley de Carrera Docente. San José, Costa Rica: Imprenta Nacional.

Rivera S. G. (2005). Constitución Política de la República de Costa Rica. Presentada y actualizada. San José, Costa Rica: Editec Editores.

Ugalde, J. (1974). Documento para sesión del Consejo Asesor Ampliado. Facultad de Educación, Universidad de Costa Rica. San José, Costa Rica: manuscrito inédito. 
Ugalde, J. (1975). Informe de labores 1974-1975. Facultad de Educación, Universidad de Costa Rica. San José, Costa Rica: manuscrito inédito.

Ugalde, J. (1978). Informe de labores 1977-1878. Facultad de Educación, Universidad de Costa Rica. San José, Costa Rica: manuscrito inédito.

Ugalde, J. (2005). Aportes al panel foro: El pensamiento filosófico de la Dra. Emma Gamboa. Cátedra "Emma Gamboa”. Facultad de Educación, Universidad de Costa Rica. San José, Costa Rica: manuscrito inédito.

Universidad de Costa Rica. (1954). Transcripción del Acta N.o 132 del Consejo Universitario. "Departamentalización de la Universidad de Costa Rica". Recuperado de http://www.cu.ucr.ac.cr/uploads/ tx_ucruniversitycouncildatabases/minute/1954/132.pdf

Universidad de Costa Rica. (1977). Transcripción del Acuerdo N.o 8 de la Sesión N.o 2346 del Consejo Universitario. "Aprobación de la nueva estructura de la Facultad de Educación". San José, Costa Rica: Autor.

Universidad de Costa Rica. (1989). Gestión del Decano de la Facultad de Educación para la creación de la Escuela de Educación Física y Deportes. Gaceta N.o 22-1989. San José, Costa Rica: Autor.

Universidad de Costa Rica. (1989). Acuerdo del Consejo Universitario sobre la transformación del Departamento de Educación Física y Deportes en Escuela. Gaceta N.o 25-1989. San José, Costa Rica: Autor.

Universidad de Costa Rica. (1990). Estatuto Orgánico. San José, Costa Rica: Oficina de Publicaciones de la Universidad de Costa Rica.

Universidad de Costa Rica y Escuela de Bibliotecología y Ciencias de la Información. (2016). Antecedentes. Recuperado de www.ebci.ucr.ac.cr

\section{BY-NC-ND}

